\title{
As condições de emergência da função reformulativa do conector quando em reportagens
}

\author{
The Conditions for the Emergence of Connector quando \\ Reformulative Function in Reports
}

Gustavo Ximenes Cunha ${ }^{1 *}$
Universidade Federal de Alfenas
Alfenas - Minas Gerais / Brasil

Resumo

Partindo de pesquisas anteriores que descreveram o conector quando como marca de reformulação, busco, no presente trabalho, uma explicação para esse uso atípico do conector em sequências textuais de reportagens. Para isso, proponho o esboço de uma abordagem que leve em conta as várias informações implicadas na emergência das funçōes dos conectores de modo geral e, como quadro metodológico, utilizo o Modelo de Análise Modular do Discurso. Ao fim do percurso de análise, foi possível constatar que a emergência da função reformulativa do quando resulta da combinação de informações de diversos módulos e formas de organização do discurso e que o uso do quando como marca de reformulação tem papel importante na forma de organização estratégica, porque está ligado à gestão das relações de faces, territórios e lugares.

Palavras-chave

Conector quando; relação de reformulação; modularidade.

*ximenescunha@yahoo.com.br 


\section{Abstract}

Departing from previous research on the reformulative function of the connector quando, this paper aims to study this atypical use of the connector in reports. The approach adopted studies the information involved in the emergence of the functions of the connectives and the methodological framework is the Modular Approach to Discourse Analysis. The results found indicate that the emergence of the reformulative function of quando emerges from the combination of several modules and forms of discourse organization and that the use of quando as a signal of reformulation has an important role in strategic organization, because it acts in the management of relation of faces, places and territories.

\section{Keywords}

Connective quando; relation of reformulation; modularity. 


\section{INTRODUÇÃO}

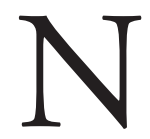

a pesquisa apresentada em Cunha (2010), foram descritas as propriedades de 28 ocorrências do conector quando presentes em um corpus formado por reportagens veiculadas em edições de janeiro de 2010 das revistas Época e Veja. Nesse corpus, a maioria das ocorrências do conector encadeia os acontecimentos, localizando-os temporalmente. Em sete dessas ocorrências, porém, o quando funciona como marca de reformulação e não como marca de relações temporais, porque introduz informações que esclarecem o sentido de expressão nominal ou de pronome presente no constituinte textual (ato) que antecede o conector. Em outros termos, verifica-se nessas ocorrências uma relação de equivalência semântica entre a expressão nominal ou o pronome e as informações trazidas pelo constituinte introduzido pelo quando ${ }^{2}$. A sequência a seguir traz uma dessas sete ocorrências:

(01) A situação política atual da Argentina não se assemelha ao começo turbulento da década

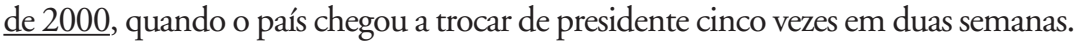

\section{(Época, "Um governo que vive de tumulto")}

Nessa sequência, o conector quando introduz um segmento que visa esclarecer o sentido da expressão o começo turbulento da década de 2000, presente no segmento que antecede o conector. Assim, o começo turbulento da década de 2000 a que o jornalista se refere diz respeito ao fato de a Argentina ter chegado a trocar de presidente cinco vezes em duas semanas. Nesse sentido, o quando equivale a uma expressão reformulativa, como a saber (CUNHA; MARINHO, 2012).

A fim de tornar menos intuitivas as análises realizadas, descrevi, em Cunha (2011), a função reformulativa das sete ocorrências do quando, por meio da aplicação destes cinco testes: 
$1^{\circ}$ : substituição do quando por expressões conectivas tipicamente temporais (depois (delque), assim que).

$2^{\circ}$ : substituição do quando por expressões conectivas tipicamente reformulativas (isto é, ou seja, a saber).

$3^{\circ}$ : substituição do quando por dois-pontos.

$4^{\circ}$ : transformação dos constituintes textuais ligados pelo quando em pergunta e resposta.

$5^{\circ}$ : inversão da ordem dos constituintes textuais ligados pelo quando.

No trabalho mencionado, a aplicação dos testes tornou a interpretação inicial mais rigorosa e ajudou a perceber que o conector quando, nas sete sequências estudadas, atua como marca de reformulação entre duas informações e não como marca de sucessão entre dois acontecimentos diferentes. Assim como um conector reformulativo e diferentemente de um conector temporal, o quando nessas sequências não pode ser substituído por conectores temporais ( $1^{\circ}$ teste), pode ser substituído por outros conectores reformulativos ( $2^{\circ}$ teste), pode ser substituído por dois-pontos ( $3^{\circ}$ teste), aceita que os atos que articula sejam transformados em pergunta e resposta ( $4^{\circ}$ teste) e não aceita a inversão desses atos ( $5^{\circ}$ teste).

Desenvolvendo os trabalhos rapidamente sumarizados, a presente contribuição parte da descrição já empreendida do conector quando como marca de reformulação para buscar uma explicação para esse uso atípico do conector. Para isso, proponho no próximo item o esboço de uma abordagem que leve em conta as várias informações implicadas na emergência das funções dos conectores de modo geral. Em seguida, apresento o Modelo de Análise Modular do Discurso, modelo com cujos instrumentos considero possível estudar os conectores na abordagem delineada. Por fim e com base nesses instrumentos, procedo à explicação do modo como, segundo minha proposta, ocorre a emergência da função reformulativa do conector quando em reportagens.

\section{EM BUSCA DE UMA ABORDAGEM PARA O ESTUDO DOS CONECTORES}

No que se refere ao papel que exerce o conector na articulação de informaçôes, as abordagens que estudam as relaçōes textuais, discursivas ou retóricas podem ser divididas em duas grandes famílias teóricas. De um lado, 
reúnem-se aquelas para as quais o conector possui papel decisivo ou mesmo determinante na articulação de porções textuais ou na marcação de uma relação. Alguns estudiosos representativos dessa vertente são Ducrot, Vogt, Moeschler, Blakemore, Rossari e Luscher. Para essas abordagens, independentemente do viés cognitivo, semântico ou textual adotado, o conector tem um papel tão relevante na construção do texto ou na articulação de enunciados que ele funcionaria como um guia para a interpretação, havendo mesmo autores, como Rossari (2000), que defendem que alguns conectores seriam criadores de relaçôes de discurso, ou seja, sem esses conectores, a relação de discurso instanciada não existiria ${ }^{3}$.

Do ponto de vista semântico, é possível dizer que essas abordagens atribuem ao conector uma carga ou bagagem semântica bastante forte, já que o conector conteria em si instruções necessárias para a interpretação da relação, funcionando como "disparadores" da realização de processos inferenciais a serem realizados pelo leitor/ouvinte (MOESCHLER, 1996). Para essas abordagens, então, o conector teria um valor semântico intrínseco e constitui, portanto, um objeto de análise bastante relevante para os estudos do texto e do discurso. Nessa perspectiva, há grande interesse na proposição de classificações dos conectores e das expressóes conectivas, conforme as instruçóes que carregam.

A pertinência dos trabalhos que se inserem nessa perspectiva está em ressaltar o papel de primeira importância que os conectores exercem na articulação do discurso e na sua interpretação. No entanto, esses mesmos trabalhos parecem se equivocar ou exagerar ao defenderem que sem o conector não seria possível estabelecer determinada relação de discurso ${ }^{4}$ ou que sem ele seria muito mais custoso, do ponto de vista cognitivo, estabelecer essa relação.

Em oposição à perspectiva mencionada, reúnem-se as abordagens que priorizam o estudo das relações de discurso, concedendo pouca atenção ao estudo dos conectores e das expressóes conectivas que podem marcar essas relaçôes. Estudiosos representativos dessa outra vertente ou família teórica são Mann, Matthiessen, Thompson, Taboada, Asher e Vieu. Nessa outra perspectiva, a pouca atenção dispensada aos conectores se deve à hipótese, contrária à da família teórica anteriormente apresentada, de que o conector não tem o poder de estabelecer uma relação de discurso e de fornecer instruçōes inferenciais seguras e inequívocas acerca das relações a serem estabelecidas no processo de interpretação. Para essas abordagens, a instabilidade dos conectores 
se traduz exatamente nas várias funções que um mesmo conector pode exercer em contextos diversos ou nas várias relações de discurso que um mesmo conector pode sinalizar (TABOADA, 2006).

Do ponto de vista semântico, é possível inferir que essas abordagens, embora não se atenham à caracterização de conectores isolados ou de grupos de conectores, atribuem ao conector uma carga semântica bastante fraca. Isso porque a relação que emerge da combinação de duas porçôes textuais articuladas por conector seria independente de seu conteúdo referencial, podendo um conector tipicamente condicional, como o se, ligar porções textuais de cuja combinação emerge uma relação de motivo ou de causa (NEPOMUCENO, 2013). Consequentemente, as relações de discurso, segundo essas abordagens, poderiam ser sempre apreendidas independentemente de qualquer sinalização ou marca de conexão (MANN; THOMPSON, 1986).

Para essas abordagens, então, o conector não teria um valor semântico intrínseco forte, não merecendo, portanto, constituir um objeto de tamanha atenção por parte dos linguistas, por não ser nem mais nem menos relevante do que qualquer outra marca linguística. Por essa razão, nessa perspectiva, não se verifica o interesse na proposição de classificações dos conectores e das expressões conectivas.

Examinando trabalhos que não atribuem papel de destaque aos conectores no estabelecimento das relaçôes de discurso, considero que sua pertinência está em chamar a atenção para a multiplicidade de funções de um mesmo conector em diferentes contextos e para o fato de que essa multifuncionalidade constitui um obstáculo à afirmação de que os conectores são absolutamente indispensáveis para a interpretação. Esses trabalhos, porém, parecem se equivocar ao utilizar esse argumento para considerá-los tão pouco relevantes a ponto de não merecerem um estudo sistemático. Se o conector é contemplado nessa perspectiva, o interesse recai nas relações de discurso que sinaliza e não no próprio conector, o que leva à percepção de que uma mesma marca pode atuar na sinalização de diferentes relações e, portanto, à conclusão de que o conector não constituiria recurso confiável para se identificar uma relação (TABOADA, 2006).

Ainda que a distinção proposta entre as duas famílias teóricas possa fornecer uma imagem simplista ou mesmo caricatural do modo como os conectores vêm sendo estudados, ela permite compreender a importância que algumas abordagens concedem ao papel dos conectores ou, ao contrário, a 
indiferença com que outras abordagens tratam essa categoria de marcadores de relações de discurso. Todavia, é importante ter em mente que, entre os dois extremos, há propostas que tendem mais para um lado ou mais para o outro, relativizando a rigidez do quadro apresentado.

Seja como for, cada família teórica, a meu ver, apresenta o inconveniente de dar demasiada ênfase para alguns aspectos importantes envolvidos na problemática das relaçôes de discurso e de desconsiderar outros aspectos igualmente importantes, o que resulta em uma compreensão inadequada ou parcial do papel dos conectores no discurso. Por isso, neste trabalho, considero necessário buscar uma hipótese alternativa em relação às duas maneiras de conceber a atuação dos conectores, hipótese que tem por base evidências colhidas nos estudos sobre o conector quando mencionados na introdução deste trabalho.

Observam Cunha (2010) e Cunha e Marinho (2012) que, ao ser empregado em reportagens, o quando pode assumir diferentes valores. Assim, ele atua na marcação principalmente de relações de discurso temporais (sucessão e regressão), mas marca ainda outras categorias de relações de discurso, como as de topicalização, argumento e reformulação. As análises realizadas revelam que a possibilidade de o conector atuar na instanciação de uma ou outra relação vai depender, entre outros fatores, do estatuto (principal ou subordinado) do constituinte textual que introduz, da instrução anafórica do conector, da natureza referencial dos segmentos textuais que conecta e da importância das informações articuladas pelo conector para o processo de negociação instaurado entre os interlocutores. Em suma, a emergência de uma ou outra função do conector (temporal, argumentativa, reformulativa, etc) parece resultar de um conjunto de fatores que se referem às instruçôes trazidas pelo próprio conector, bem como a diferentes planos da organização discursiva.

Com base nos resultados desses trabalhos e buscando dar conta desses fatores, levanto a hipótese de que cada conector possui uma bagagem semântica rica (e não forte ou fraca), que abarca todos os valores ou nuances de sentido que, num determinado estágio sincrônico da língua, ele pode exibir em diferentes contextos linguísticos e situacionais. Nesse sentido, o quando seria um conector cuja bagagem semântica rica abarca um conjunto definido e limitado de valores, como sucessão, regressão, topicalização, argumento e reformulação. Como revelado em Cunha (2010) e Cunha e Marinho (2012), é possível que os valores 
temporais (sucessão e regressão) sejam instanciados com maior frequência pelos interlocutores, o que faz do quando um conector tipicamente temporal, mas isso não impede que ele seja empregado com um dos outros valores que abarca, dependendo do contexto linguístico e/ou do situacional em que ocorre.

Sendo assim, nas ocorrências particulares de um dado conector, esses contextos linguístico e situacional agem na atualização do valor considerado o mais relevante pelo produtor do texto. Por contexto linguístico, entendo, entre outros elementos, as informações articuladas pelo conector, a hierarquia dos constituintes textuais por ele ligados, o tópico em que o ato introduzido pelo conector se encadeia, etc. Por contexto situacional, entendo o gênero do discurso a que pertence o texto em que ocorre o conector, a materialidade da interação que se dá entre os interlocutores, as relações de face, territórios e lugares entre esses interlocutores, etc.

Segundo a hipótese proposta, o estudo das ocorrências de um conector deve levar em conta, então, não só a rica bagagem semântica do conector, aquela que, em virtude da recorrência dos usos particulares, foi se constituindo ao longo do tempo. Esse estudo deve levar em conta também as características dos contextos linguístico e situacional que serão responsáveis pela emergência de uma dada função do conector considerado.

Assim, a noção de condiçôes de emergência empregada no título deste trabalho busca dar conta do fato de que é sempre um conjunto complexo de fatores, pertencentes a diferentes planos da organização do discurso, que, combinados, provocam a emergência de um determinado fenômeno linguístico. Nesse sentido, a atribuição de determinado valor a um conector não se deve apenas às propriedades semânticas desse conector, às suas propriedades sintáticas, ao lugar da estrutura textual em que ele surge, ao conteúdo referencial dos constituintes que articula ou ao gênero do discurso a que pertence o texto considerado, mas se deve à combinação de todos esses fatores num determinado momento.

Dessa forma, a hipótese que subjaz a este estudo do quando reformulativo implica levar em conta informações de diferentes naturezas: lexicais, semânticas, sintáticas, referenciais, textuais, informacionais, interacionais, etc. Para isso, fazse necessário dispor de um modelo de análise que possua instrumentos capazes de descrever e explicar de maneira consistente a organização global do discurso, ou seja, os fatores pertencentes a diferentes planos da organização discursiva que 
podem contribuir para a emergência de uma ou de outra função de um conector. Em vista dessa exigência e para verificar a pertinência e o alcance da hipótese aqui levantada, este trabalho se vale do arcabouço teórico e metodológico do Modelo de Análise Modular do Discurso, o qual será apresentado no próximo item.

\section{UM MODELO MULTIDIMENSIONAL DA COMPLEXIDADE DISCURSIVA}

O Modelo de Análise Modular do Discurso constitui um instrumento de descrição e explicação da complexidade discursiva. Em sua versão atual (FILLIETTAZ, 2004; FILLIETTAZ; ROULET, 2002; MARINHO, 2004; MARINHO; PIRES; VILLELA, 2007; ROULET; FILLIETTAZ; GROBET, 2001), o modelo compõe um quadro teórico e metodológico que visa reunir, em uma mesma abordagem da complexidade da organização do discurso, as contribuições de pesquisadores que se centraram em aspectos isolados dessa organização.

O esforço pela criação de um modelo, ao mesmo tempo, amplo e preciso justifica-se pela seguinte constatação:

a construção e a interpretação do discurso são submetidas a três tipos de restriçôes: restrições que podemos chamar situacionais, ligadas ao universo de referência e à situação de interação; restriçōes linguísticas, ligadas à sintaxe e ao léxico da (ou das) variedade(s) de língua(s) utilizada(s), e restriçôes textuais, ligadas à estrutura hierárquica do texto (ROULET; FILLIETTAZ; GROBET, 2001, p. 44).

Por isso, o modelo modular constitui um quadro de análise, que permite integrar e articular, em uma perspectiva cognitivo-interacionista, as dimensões linguística, textual e situacional da organização do discurso.

Reconhecendo que o discurso é um objeto cuja organização e cujo funcionamento envolvem aspectos dessas diferentes dimensões, Roulet (ROULET; FILLIETTAZ; GROBET, 2001) encontra na modularidade um método satisfatório para dar conta da organização do discurso. Distanciando-se de abordagens cognitivistas, como a de Fodor, Roulet se vale das contribuições de estudiosos como Simon e Nølke, para os quais o estudo modular de sistemas complexos constitui uma abordagem metodológica, que visa descrever 
a organização do discurso e não o funcionamento da mente. Com base nesse método, a identificação e a combinação dos subsistemas permitem a compreensão progressiva do objeto complexo que deu origem a esses subsistemas (FILLIETTAZ; ROULET, 2002).

Ao aplicar esse método ao estudo do discurso, o modelo modular considera ser possível descrever, por exemplo, o sistema da língua independentemente da situação de interação em que ela é utilizada, bem como descrever as estruturas sintáticas de uma produção discursiva sem fazer referência à estrutura conceitual que subjaz a ela. Descritas de modo independente as informaçôes que participam da organização do discurso, o modelo postula ainda que essas informações podem ser combinadas, a fim de se descreverem os diferentes aspectos envolvidos na produção e na interpretação dessa organização complexa que é o discurso. Dessa forma, a abordagem modular implica uma dupla exigência:

a) decompor a organização complexa do discurso em um número limitado de sistemas (ou módulos) reduzidos a informaçōes simples e b) descrever de maneira tão precisa quanto possível a forma como essas informações simples podem ser combinadas para dar conta das diferentes formas de organização dos discursos analisados (ROULET; FILLIETTAZ; GROBET, 2001, p. 42).

Conforme essa metodologia, identificam-se inicialmente os módulos que entram na composição do discurso. Um módulo é definido como um sistema de informações elementares, o qual deve fornecer a descrição de um domínio específico da organização discursiva. Nessa abordagem, considera-se que cada dimensão do discurso se constitui de módulos. Assim, a dimensão linguística se constitui dos módulos lexical e sintático; a dimensão textual se constitui do módulo hierárquico; e a dimensão situacional se constitui dos módulos interacional e referencial.

Definidos os módulos, é possível descrever e explicar, em seguida, como as informações modulares se combinam em formas de organização do discurso. $\mathrm{Na}$ produção e na interpretação de toda forma discursiva, as informações de origem modular se interrelacionam em unidades complexas de análise, que são as formas de organização. No modelo modular, distinguem-se dois tipos de formas de organização: as elementares e as complexas. As formas de organização elementares (fonoprosódica, semântica, relacional, informacional, enunciativa, sequencial, operacional) resultam da combinação ou acoplagem de informações 
extraídas dos módulos. Já as formas de organização complexas (periódica, tópica, polifônica, composicional, estratégica) resultam da combinação ou acoplagem de informaçōes extraídas dos módulos e das formas de organização elementares e/ou complexas.

Neste estudo, analisei as sete sequências textuais examinadas em Cunha (2011), em que o conector quando atua como marca de reformulação. Num primeiro momento, as sequências e as reportagens em que ocorrem foram investigadas do ponto de vista dos módulos referencial, lexical, hierárquico e sintático. Em seguida, as informações resultantes do estudo dos módulos foram combinadas em três formas de organização: relacional, informacional e estratégica. Esse percurso de análise mostrou-se satisfatório para se chegar a uma explicação do modo como emerge a função reformulativa do quando nas sequências. Apresento a seguir os resultados das análises.

\section{RESULTADOS DAS ANÁLISES DAS OCORRÊNCIAS DO QUANDO REFORMULATIVO}

\subsection{Informações resultantes das análises de módulos}

Nos itens que seguem, os estudos não se prendem apenas ao conector quando, mas se ocupam também dos contextos linguístico e situacional em que ele é empregado. Assim, o estudo dos módulos referencial e hierárquico se ocupa da descrição dos contextos linguístico e situacional do conector, para compreender o ambiente em que ele é empregado. Já o estudo do módulo lexical busca lançar luz sobre as instruções do conector. Por fim, no estudo do módulo sintático, focalizam-se tanto o papel do conector na conexão de segmentos linguísticos quanto propriedades sintáticas desses segmentos.

\subsubsection{Módulo referencial}

De modo geral, esse módulo tem como finalidade estudar as relações que o discurso mantém com o mundo no qual é produzido, bem como as relações que mantém com os mundos que representa.

Considerando o mundo em que o discurso se insere, verifica-se que as sete sequências em análise entram na composição de produçôes discursivas 
pertencentes ao gênero reportagem. Nesse gênero, o autor (jornalista) detém um conhecimento que, a princípio, o leitor não detém, tendo em vista o acesso a fontes (pessoas, órgãos, documentos) às quais este não poderia ter acesso. Além disso, as revistas semanais de informação de onde foram extraídas as reportagens (Época e Veja) são consideradas veículos de comunicação de referência, o que contribui para dar legitimidade à fala daqueles que produzem reportagens, tornando-a uma voz institucionalmente autorizada.

Visto dessa forma, o vínculo que se estabelece entre os interactantes por meio das reportagens poderia ser perigoso para a gestão das relações de faces e de territórios ${ }^{5}$, uma vez que o leitor já entraria nessa interação consciente da posição inferior que lhe é destinada, posição de um parceiro mudo e ignorante dos tópicos abordados e desprovido de uma chancela institucional (CUNHA, 2013).

Como a recusa do leitor em participar da interação seria prejudicial para quem produz um objeto de consumo, tal como uma revista semanal de informação, a saída adotada pelos veículos de comunicação considerados de referência é, então, a de construir um narrador que se apresenta como um prestador de serviço público, como um jornalista cuja função, por dever ético, é informar o leitor acerca do que outros (instituiçōes, governos, empresas, etc.) tentam ocultar. Ao se apresentar dessa forma, o jornalista justifica a tomada da palavra e, em consequência, a invasão do território do leitor.

Ao mesmo tempo, faz parte dessa saída construir um narratário ou uma figura de leitor correspondente à do cidadão que se interessa pelo que ocorre no espaço público e que exige que o jornalista cumpra o seu papel de colher e de divulgar (revelar) informações ocorridas nesse espaço. Constrói-se, assim, a figura de um leitor que, tendo em vista os deveres e os direitos do cidadão, permite que o jornalista invada seu território, desde que este tome a palavra para tratar de tópicos de interesse da coletividade.

Como se vê, no mundo em que as sequências foram produzidas, é bastante complexa a forma como os interactantes fazem a gestão das relações de faces e de territórios, o que tem impacto sobre a escolha dos recursos usados para sinalizar a articulação das sequências, como será mostrado adiante, na forma de organização estratégica.

Do ponto de vista do mundo que o discurso representa, focalizo as informaçôes veiculadas apenas nas sete sequências analisadas neste trabalho e não nas reportagens completas. Entre as informaçōes ativadas pelos atos, verifica- 
se, independentemente da presença do quando, uma equivalência semântica, já que a informação à direita do conector especifica o sentido de expressão ou de pronome à sua esquerda. Nessa perspectiva, os conceitos ativados no constituinte introduzido pelo quando derivam diretamente dos conceitos ativados pelo constituinte que o antecede. É o que revela esta sequência:

(02) A última intervenção [militar dos EUA no Haiti] ocorreu em 1994, quando militares americanos ajudaram a levar ao poder o ex-padre católico Jean-Bertrand Aristide.

(Época, "O futuro brasileiro no Haiti”)

Nessa sequência, a última intervenção militar dos EUA no Haiti é a expressão que será reformulada no constituinte introduzido pelo quando. Assim, essa intervenção militar, informação ativada à esquerda do conector, é a atitude de militares americanos de ajudarem a levar ao poder o ex-padre católico Jean-Bertrand Aristide, informação ativada à direita do conector. Constata-se, então, que a atitude realizada pelos militares deriva diretamente do conceito última intervenção militar dos EUA no Haiti. A percepção de que os conceitos articulados pelo quando derivam diretamente um do outro será de fundamental importância para o estudo da forma de organização informacional.

\subsubsection{Módulo lexical}

No modelo modular, esse módulo é o responsável por definir a pronúncia, a ortografia, as propriedades gramaticais e o sentido das palavras das diferentes variedades linguísticas.

Nas sequências em que o conector quando atua como marca de reformulação, é possível caracterizá-lo por meio de três propriedades ou traços. A primeira propriedade diz respeito à natureza anafórica do conector. Conforme Berrendoner (1983), todos os conectores são anafóricos, uma vez que sempre articulam a informação que introduzem a uma informação previamente estocada na memória discursiva ${ }^{6}$. No caso do quando reformulativo, ele sempre se ancora em informação ativada por termo (expressão nominal, adjunto adverbial) presente no constituinte que o antecede. Esse termo pode ser aquele que será reformulado no constituinte que o quando introduz ou pode ser um outro termo. 
A segunda propriedade que ajuda a caracterizar o quando reformulativo do ponto de vista lexical é o traço temporal. As análises revelaram que todas as expressões em que o quando se ancora, no constituinte que o antecede, exibem uma natureza temporal, porque sempre se referem a uma data, uma época ou um período histórico (em 1994, em junho, em setembro, a redemocratização do país, da crise de 2008, ao começo turbulento da década de 2000, no dia 23 de dezembro).

A terceira propriedade característica do quando reformulativo é a da conexão, ou seja, esse item lexical atua não no interior de uma proposição, como um operador ou como o advérbio quando (Quando ele sai?), mas na junção de porçôes textuais, como um conector.

A combinação desses três traços ou propriedades, [anáfora], [tempo] e [conexão], é a responsável por fazer com que o quando reformulativo possa ser aproximado de um pronome relativo e não de uma conjunção temporal, já que o quando, como conjunção, não se ancora em nenhuma informação ativada por termo presente no constituinte que o antecede. Como veremos na análise do módulo sintático, são essas propriedades combinadas que impedem a alteração na ordem dos constituintes ligados pelo quando reformulativo.

\subsubsection{Módulo hierárquico}

No estudo desse módulo, considera-se que toda interação verbal se caracteriza por um processo de negociação em que os interactantes iniciam proposiçóes, reagem a elas e as ratificam. Conforme Roulet (ROULET; FILLIETTAZ; GROBET, 2001, p. 57), "toda intervenção linguageira (cumprimento, pedido, asserção, etc) constitui uma PROPOSIÇÃO, que desencadeia um processo de negociação entre os interactantes". A negociação conjunta dos interactantes leva à construção de unidades textuais complexas. Assim, toda unidade textual corresponde a uma realização efetiva desse processo e é representada por meio de estruturas hierárquicas.

Com a estrutura hierárquica, é possível a descrição das hierarquias e das relaçõos existentes entre os constituintes do texto - trocas, intervenções e atos. Essas relações são de três tipos: dependência (a presença de um constituinte textual está ligada à presença do outro), interdependência (um constituinte não pode existir sem o outro, como ocorre, por exemplo, em uma troca formada por pergunta e resposta) e independência (a presença de um constituinte não está ligada à presença de outro). 
Nas sequências estudadas neste trabalho, os constituintes introduzidos pelo quando reformulativo têm, como já verificado em Cunha e Marinho (2012), o estatuto de principais, ou seja, são de fundamental importância para o processo de negociação instaurado entre autor e leitor. O estatuto de principais desses constituintes pode ser verificado, conforme propõe Roulet (2006), pela impossibilidade de suprimi-los, por trazerem a informação central ou a mais relevante das sequências.

(03) O primeiro exemplo [de erro político cometido pelo então prefeito de São Paulo, Kassab] ocorreu em junho, quando a prefeitura restringiu a circulação de ônibus fretados "para dar fluidez ao trânsito".

(Época, "Na lama com Kassab")

Nessa sequência, o ato introduzido pelo quando tem o estatuto de principal, porque é esse ato que traz a informação central do trecho, não podendo, portanto, ser suprimido. Afinal, para o leitor da reportagem "Na lama com Kassab", importa saber qual foi o primeiro exemplo de erro político cometido por Kassab (ato principal) e não que esse primeiro exemplo ocorreu em junho (ato subordinado). E a informação sobre qual foi o primeiro exemplo de erro político é dada no ato introduzido pelo quando. É o que representa esta estrutura hierárquica ${ }^{7}$ :

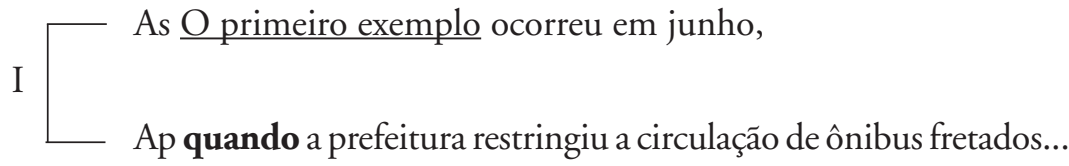

As análises do módulo hierárquico são especialmente importantes para o estudo da forma de organização relacional, que será realizado adiante.

\subsubsection{Módulo sintático}

Esse módulo trata das regras que definem as categorias e a construção das estruturas das sentenças.

A análise revelou que, à maneira das sequências cujas informações se articulam pela relação de finalidade (ROULET; FILLIETTAZ; GROBET, 
2001), as sequências em que o quando reformulativo ocorre manifestam uma contradição entre os planos sintático e hierárquico da organização do discurso. O constituinte introduzido pelo quando é, como vimos, principal no plano textual ou hierárquico, mas é subordinado no plano sintático. Assim, enquanto, no plano hierárquico, esse constituinte é fundamental para o processo de negociação, não podendo ser suprimido, do ponto de vista sintático ele pode ser classificado tradicionalmente como uma oração subordinada adjetiva explicativa, que traz uma informação complementar à oração principal.

Nas sequências em análise, essa oração subordinada vai esclarecer ou explicitar o sentido de pronome ou expressão presente na oração principal. Por isso, o quando nessas sequências exibe, como dito na análise do módulo lexical, um comportamento de pronome relativo (advérbio relativo (BECHARA, 2009)), que remete a algum sintagma da oração principal.

(04) (Oração principal) Foi o que ocorreu na semana passada, (Oração subordinada adjetiva explicativa) quando o governo venezuelano suspendeu o sinal do canal a cabo RCTV, a emissora mais antiga do país, e de outros cinco pequenos canais independentes.

$$
\text { (Época, "A conta do autoritarismo") }
$$

Nessa sequência, o quando, remetendo à expressão adverbial na semana passada, introduz uma adjetiva explicativa que esclarece o que ocorreu na semana passada: "o governo venezuelano suspendeu o sinal do canal a cabo RCTV, a emissora mais antiga do país, e de outros cinco pequenos canais independentes".

Como veremos no estudo da forma de organização relacional, a função que a oração introduzida pelo quando exerce no nível sintático justifica, em parte, a emergência da relação de reformulação.

Quanto à ordem das oraçôes ligadas pelo quando reformulativo, ela evidencia uma natureza fixa, uma vez que a oração subordinada introduzida pelo quando sempre segue a oração principal, ou seja, as sequências analisadas são orações complexas, em que a ordem é sempre <oração principal oração subordinada>.

(05) (Oração principal) Kassab voltou a demonstrar o mesmo tipo de fraqueza em setembro, (Oração subordinada) quando anunciou a redução de cinco para quatro no total de merendas diárias de 60 mil crianças das creches do período integral.

(Época, "Na lama com Kassab") 
Diferentemente do que ocorre com sequências em que o quando introduz uma adverbial temporal, nas sequências aqui analisadas as orações não podem ser invertidas. Como mostrado em Cunha (2011), a inversão das orações articuladas pelo quando reformulativo altera o sentido original. Com a inversão, as orações passam a expressar dois fatos diferentes e não um fato apresentado na primeira oração e reformulado na segunda. Vejamos como isso ocorre, alterando a ordem das oraçōes do exemplo anterior:

(06) Quando anunciou a redução de cinco para quatro no total de merendas diárias de 60 mil crianças das creches do período integral, Kassab voltou a demonstrar o mesmo tipo de fraqueza em setembro.

A inversão modifica a compreensão da sequência, porque faz com que a oração introduzida pelo quando seja lida como uma adverbial temporal, que estabelece uma baliza temporal para a oração principal, e não mais como uma adjetiva explicativa, que esclarece o sentido de termo presente na oração principal. Assim, em (05), há uma relação de equivalência semântica entre o mesmo tipo de fraqueza demonstrado por Kassab (oração principal) e o anúncio da redução no número de merendas (oração subordinada). Para o jornalista, esse anúncio é uma evidência de fraqueza de Kassab. Mas, em (06), o anúncio feito pelo então prefeito de São Paulo e o mesmo tipo de fraqueza passam a ser lidos como fatos diferentes. A oração introduzida pelo quando passa a expressar o momento em que o prefeito demonstrou o mesmo tipo de fraqueza.

\subsection{Informações resultantes das análises de formas de organização}

Nos itens a seguir, as informações resultantes do estudo dos módulos serão combinadas nas formas de organização relacional, informacional e estratégica. Nesta etapa, a combinação de informações modulares permitirá aprofundar as análises realizadas até o momento e alcançar uma explicação consistente para a emergência da função reformulativa do conector quando em reportagens.

\subsubsection{Forma de organização relacional}

Nessa forma de organização, a combinação de informações hierárquicas, lexicais, sintáticas e referenciais permite descrever a hierarquia entre os constituintes do texto, bem como as relações de discurso que se estabelecem 
entre esses constituintes e informações da memória discursiva. Em textos monologais, como as reportagens, as relações de discurso entre um constituinte textual e uma informação da memória discursiva, frequentemente com origem no próprio texto, são estudadas com base em oito categorias genéricas de relaçôes discursivas: argumento, contra-argumento, reformulação, topicalização, sucessão, preparação, comentário e clarificação (MARINHO, 2002, CUNHA, 2012).

Em todas as sequências estudadas neste trabalho, entre o constituinte introduzido pelo conector quando e a informação estocada na memória discursiva, constata-se a relação de reformulação. A emergência dessa relação está ligada, ao menos em parte, à natureza sintática do constituinte introduzido pelo quando. Como exposto no item anterior, esse constituinte atua, no nível sintático, como uma oração adjetiva explicativa. Ao trazer uma explicação, a oração reformula o sentido de termo já mencionado, tornando-o mais claro para o leitor.

Conforme Rossari (1993, 2000), a categoria genérica de reformulação se subdivide em duas subcategorias: a parafrástica e a nãoparafrástica. A parafrástica se caracteriza pela existência de uma equivalência semântica entre dois constituintes textuais (atos ou intervençôes). Já a nãoparafrástica permite ao locutor operar uma retrointerpretação da informação expressa no primeiro constituinte textual.

Dada a equivalência semântica entre o termo reformulado e a informação introduzida pelo quando, equivalência já apontada no estudo do módulo referencial, a relação marcada por esse conector, nas sequências analisadas, é a de reformulação parafrástica. Por isso, o quando, nessas sequências, pode ser substituído pela expressão a saber ou por dois-pontos (CUNHA, 2011, CUNHA; MARINHO, 2012).

(07) A última intervenção [militar dos EUA no Haiti] ocorreu em 1994, a saber, militares americanos ajudaram a levar ao poder o ex-padre católico Jean-Bertrand Aristide.

(Época, "O futuro brasileiro no Haiti”)

(08) A última intervenção [militar dos EUA no Haiti] ocorreu em 1994: militares americanos ajudaram a levar ao poder o ex-padre católico Jean-Bertrand Aristide. 
No entanto, vale informar que, mesmo funcionando como marca de reformulação, o quando preserva, em menor medida, uma carga ou valor semântico temporal, devido ao fato de sempre remeter a um sintagma temporal presente no ato à sua esquerda.

\subsubsection{Forma de organização informacional}

Essa forma de organização combina informações hierárquicas, referenciais, lexicais e sintáticas, com o objetivo de analisar a estrutura informacional do discurso, descrevendo as diferentes formas de progressōes informacionais que se manifestam na sucessão dos atos (GROBET, 2000, CUNHA, 2008, 2009).

Nas sequências em análise, o termo reformulado e presente no ato à esquerda do conector ativa uma informação que, uma vez estocada na memória discursiva, passa a funcionar como ponto de ancoragem imediato (tópico) do ato à direita do conector ${ }^{8}$. Em outros termos, o tópico do ato introduzido pelo quando é a informação ativada pelo termo reformulado, porque é dessa informação que o ato seguinte trata. É o que evidencio com esta sequência.

(09) A situação política atual da Argentina não se assemelha ao começo turbulento da década de 2000, quando o país chegou a trocar de presidente cinco vezes em duas semanas.

(Época, "Um governo que vive de tumulto")

$\mathrm{O}$ ato à esquerda do conector ativa a informação $o$ começo turbulento da década de 2000. Estocada na memória discursiva, essa informação passa a constituir o tópico do ato introduzido pelo quando. Afinal, é do começo turbulento da década de 2000 que trata esse ato.

A possibilidade de o termo reformulado se tornar o tópico do ato que o quando introduz se explica pela função que esse ato exerce no nível sintático (oração adjetiva explicativa). Por complementar o sentido de termo presente à esquerda do conector, o ato introduzido pelo quando se encadeia na informação ativada por esse termo, esclarecendo-o.

Em todas as ocorrências, o quando funciona como traço de ponto de ancoragem, porque sinaliza o encadeamento do ato que introduz em informação da memória discursiva sempre com origem no ato anterior. Nesse sentido, o 
quando se aproxima do onde. Em estudo sobre este conector, Marinho (2002) mostra que o onde, ao funcionar como marca do encadeamento de um ato em uma informação da memória discursiva, pode exercer papel importante na forma de organização informacional.

A informação da memória discursiva em que o quando se encadeia pode ser o ponto de ancoragem imediato (tópico) ou pode ser um ponto de ancoragem de segundo plano, informação que, embora semiativa e facilmente acessível na memória discursiva, não exerce papel fundamental ou primordial no encadeamento dos atos (GROBET, 2000). O quando funciona como marca de ancoragem no tópico (ou como traço tópico) nas ocorrências em que ele retoma a informação ativada pelo termo a ser reformulado. Todavia, esse mesmo conector funciona como traço de ponto de ancoragem de segundo plano nas ocorrências em que retoma informação ativada por outro termo ou por somente uma parte do termo reformulado.

Na sequência abaixo, o quando atua como traço tópico:

(10) Embora ruidosa, é improvável que essa crise tome as proporçôes da crise de $\underline{2008}$, quando uma disputa entre governo e produtores rurais mobilizou panelaços e manifestaçóes por toda a Argentina.

(Época, "Um governo que vive de tumulto")

Nessa sequência, o quando se encadeia na informação ativada pela expressão da crise de 2008. Essa informação constitui o tópico do ato introduzido pelo conector, porque todo esse ato tem como função trazer esclarecimentos sobre a crise ocorrida em 2008, na Argentina.

$\mathrm{Na}$ sequência abaixo, o quando exerce o papel de traço de ponto de ancoragem de segundo plano:

(11) O primeiro exemplo [de erro político cometido pelo então prefeito de São Paulo, Kassab] ocorreu em junho, quando a prefeitura restringiu a circulação de ônibus fretados "para dar fluidez ao trânsito".

(Época, "Na lama com Kassab")

$\mathrm{O}$ ato introduzido pelo quando traz esclarecimentos sobre qual foi o primeiro exemplo de erro político cometido por Kassab. Entretanto, o conector 
não se encadeia na expressão o primeiro exemplo e sim na expressão adverbial em junho, o que faz dessa ocorrência do quando, no nível informacional, um traço de ponto de ancoragem de segundo plano e não um traço tópico.

Nas sete sequências em estudo, o quando funcionou como traço tópico em três ocorrências. Nas outras quatro, ele funcionou como traço de ponto de ancoragem de segundo plano.

\subsubsection{Forma de organização estratégica}

Essa forma de organização tem por objetivo descrever o modo como os interactantes coordenam as relações de faces, de territórios e de lugares no discurso, passando, como nota Burger (1995), da descrição à explicação dos comportamentos, em termos de estratégias. No estudo da gestão dessas relações, combinam-se informações acerca das noções de face e território, definidas no módulo referencial, com informações de outros módulos e formas de organização, para verificar, em especial, como os interactantes realizam os processos de figuração, isto é, estratégias para reduzir as ameaças às suas faces e aos seus territórios (ROULET; FILLIETTAZ; GROBET, 2001, RUFINO, 2011, CUNHA, 2013).

Do ponto de vista estratégico, a relação de reformulação pode ser considerada como potencialmente agressiva para a face do interlocutor. Isso porque, ao reformular um segmento de seu discurso, tornando-o mais claro, o locutor evidencia para seu interlocutor acreditar que este desconhece o sentido ou o significado desse segmento. Sendo assim, o ato de reformular coloca aquele que reformula numa posição superior em relação ao interlocutor ou no lugar de alguém que detém uma informação que o outro supostamente desconhece. De modo complementar, esse ato coloca o interlocutor na posição de alguém que, para compreender o que é dito, precisa da colaboração do locutor, que deve se valer de recursos facilitadores de acesso ao sentido. Esta sequência, extraída de um guia alimentar do Ministério da Saúde, permite evidenciar a questão?:

(12) Procedimentos incorretos de manipulação dos alimentos podem causar as DTA, ou seja, doenças em que os alimentos ou a água atuam como veículo para transmissão de organismos prejudiciais à saúde ou de substâncias tóxicas. 
No trecho, o autor se apresenta como detentor de um conhecimento que supostamente o leitor não possui. Ao reformular o termo DTA, o autor do guia demonstra conhecer o significado desse termo e, ao mesmo tempo, explicita a sua hipótese de que, para ele, o leitor desconhece esse mesmo significado. Caso contrário, não teria reformulado o termo. Por mostrar que detém um conhecimento especializado de que supostamente o outro não dispõe, o autor coloca-se numa posição superior em relação ao interlocutor. Ao interagir com o leitor por meio do guia, o autor o imagina como alguém que desconhece termos médicos específicos e que, portanto, precisa do seu auxílio, em termos do emprego de recursos facilitadores, para compreender o que é informado e para se precaver de doenças ao manipular alimentos.

A potencial agressividade da relação de reformulação pode não comprometer o desenvolvimento de uma interação em contextos em que o papel social assumido pelo locutor o coloca previamente numa posição superior, isto é, em contextos socialmente assimétricos (KERBRAT-ORECHIONNI, 2006). Um contexto desse tipo é, por exemplo, o do guia apresentado anteriormente. Nele uma instância governamental (o Ministério da Saúde) dialoga com a população e não com especialistas em nutrição. Nesse contexto, os papéis assumidos pelos interlocutores amenizam a potencial agressividade da relação de reformulação, e o desenvolvimento da interação pode não sofrer abalo, já que o leitor comum, não especialista em nutrição, não sentirá que sua face sofreu ataque e não se verá diminuído ou agredido por desconhecer termos que o outro conhece.

Outro contexto em que a relação de reformulação pode não comprometer o desenvolvimento da interação é o da sala de aula. Na sala de aula, o locutor assume o papel de alguém (o professor) que possui um conjunto de informações que o interlocutor (o aluno) não detém, mas quer passar a deter. Nesse contexto, o ato de reformular informações é previsto e até mesmo desejado.

Entretanto, diferentemente dos contextos apresentados, no contexto jornalístico, o ato de reformular pode comprometer o desenvolvimento da interação. Como apontado no estudo do módulo referencial, nesse contexto, o jornalista ocupa um lugar alto ou dominante, por dispor de um conhecimento de que, a princípio, o leitor não dispõe. E o fato de as revistas estudadas neste trabalho serem consideradas veículos de comunicação de referência contribui para a colocação do jornalista em posição superior, porque confere legitimidade à sua fala. 
O vínculo que se estabelece entre esses interlocutores pode ser perigoso para a gestão das relaçôes de faces e de territórios, porque o leitor participa dessa interação sabendo que a posição que lhe cabe é a de um parceiro sem direito à fala, ignorante dos tópicos tratados e desprovido de uma chancela institucional. Esse tipo de vínculo é profundamente problemático para quem, como o jornalista, produz um objeto de consumo, como uma revista semanal de informação, já que o leitor poderia se recusar a participar da interação (ou a comprar outros exemplares do veículo de comunicação).

Por esse motivo e para que a interação possa se desenrolar a bom termo, o autor assume o papel de jornalista/prestador de serviço público e reserva ao leitor o papel de cidadão a quem tem o dever (ético) de informar. Nesse contexto, o jornalista é, então, levado a empregar uma série de estratégias discursivas para proteger a face do leitor e amenizar os riscos da invasão ao seu território (CUNHA, 2013).

Para suavizar a potencial agressividade da relação de reformulação para as faces e os territórios em jogo, o jornalista pode ser levado a adotar, pelo menos, três estratégias discursivas. A primeira é evitar a reformulação, ou seja, não articular informações do texto por meio da relação de reformulação. Essa estratégia se evidencia na baixa frequência da relação de reformulação em gêneros jornalísticos, como revelam estudos sobre a reportagem e a notícia ${ }^{10}$.

Outra estratégia para amenizar a agressividade da relação de reformulação é, havendo uma relação de reformulação entre informações, não a sinalizar por meio de nenhuma marca, como ocorre nas reportagens estudadas em Cunha (2013). Nesse trabalho, as treze relações de reformulação identificadas não apresentam nenhuma marca. Uma relação de reformulação não marcada pode passar despercebida pelo leitor, que poderá não se sentir na posição de alguém a quem é preciso dar condições de acesso ao sentido.

A terceira estratégia é a que mais diretamente interessa a este trabalho, uma vez que diz respeito à atitude de sinalizar a relação de reformulação por meio de marcas atípicas, como o quando. Em outros termos, para "disfarçar" a relação de reformulação e não explicitar a suposição de que o leitor precisa de auxílio para compreender o que é dito, o produtor do texto pode sinalizar essa relação com marcas consideradas típicas de outras relações.

Com o quando, marcador típico ou mais frequente de relações temporais (CUNHA; MARINHO, 2012), a relação de reformulação não é explicitada de modo ostensivo, como o seria por expressões tipicamente reformulativas, como 
isto é e ou seja. Com esse conector, o jornalista faz parecer que seu objetivo é apenas o de ligar duas oraçóes por meio de um pronome relativo (o quando), o qual teria apenas um papel no encadeamento de informaçóes ou na retomada de informação de natureza temporal expressa na oração que o precede. Desse modo, verifica-se que o emprego do quando reformulativo tem papel decisivo na forma de organização estratégica, uma vez que o seu emprego constitui um dos recursos de que o jornalista se utiliza para amenizar possíveis agressões à face do leitor e, consequentemente, não comprometer o desenvolvimento da interação.

Ao fim desse percurso de análise, verifica-se que a emergência do valor reformulativo do quando se deve à combinação de fatores ligados aos contextos situacional e linguístico em que o conector é utilizado. Esse valor emerge em contextos situacionais em que a explicitação da relação de reformulação por meio de conectores reformulativos típicos tornaria problemática a gestão das relações de faces, territórios e lugares entre os interlocutores. E emerge também em contextos linguísticos em que o quando articula informações semanticamente equivalentes, introduz oração adjetiva explicativa, encabeça constituinte textual principal, atua como traço de ponto de ancoragem e retoma expressão de natureza temporal.

\section{CONSIDERAÇÕES FINAIS}

Neste trabalho, apresentei um estudo do conector quando como marca de reformulação. Partindo das descrições desse conector desenvolvidas anteriormente em Cunha (2010, 2011) e em Cunha e Marinho (2012), o estudo aqui empreendido procurou explicar esse funcionamento atípico ou menos frequente do quando, evidenciando que a emergência da função reformulativa desse conector mobiliza informações de diferentes planos da organização do discurso.

Para isso, delineei inicialmente uma abordagem para o estudo dos conectores, segundo a qual cada conector possui uma bagagem semântica rica, tendo em vista todos os valores ou nuances de sentido que, num determinado estágio sincrônico da língua, ele pode apresentar em diferentes contextos linguísticos e situacionais. Ainda segundo essa abordagem, o estudo das ocorrências de um conector deve levar em conta não só as instruções ligadas ao conector, mas também elementos componentes desses contextos linguísticos 
e situacionais que serão responsáveis pela emergência de uma dada função do conector considerado.

Nesse sentido, a emergência de uma dada função tem sempre como causa um conjunto complexo de fatores, pertencentes a diferentes planos da organização do discurso. Sendo assim, o estudo de um conector implica levar em conta informações de naturezas diversas: lexicais, semânticas, sintáticas, referenciais, textuais, informacionais, interacionais, etc. Para isso, foi necessário adotar, como referencial teórico e metodológico de base, o Modelo de Análise Modular do Discurso, uma vez que esse modelo permite descrever e explicar de maneira consistente a organização global do discurso, identificando os fatores pertencentes a diferentes planos da organização discursiva que podem contribuir para a emergência de uma ou de outra função de um conector.

Neste trabalho, a primeira etapa do estudo do quando reformulativo consistiu na análise das sequências do corpus do ponto de vista dos módulos referencial, lexical, hierárquico e sintático. Posteriormente, as informações resultantes do estudo dessa primeira etapa foram combinadas nas análises das formas de organização relacional, informacional e estratégica. Ao fim do percurso, constatou-se que a combinação de informações de todos esses módulos e formas de organização é uma condição para a emergência da função reformulativa do quando ou para que o valor reformulativo desse conector se sobreponha aos demais valores constantes de sua bagagem semântica. Constatou-se também que o uso do quando como marca de reformulação tem papel importante na forma de organização estratégica, porque está profundamente ligado à gestão das relações de faces, territórios e lugares. Tendo em vista o caráter potencialmente agressivo da relação de reformulação, o jornalista ameniza essa "agressividade", marcando a relação com uma marca atípica, que é o conector quando.

\section{NOTAS}

${ }^{1}$ Doutor em Linguística pela Universidade Federal de Minas Gerais (UFMG) e Professor Adjunto da Universidade Federal de Alfenas (Unifal-MG).

${ }^{2}$ Um desenvolvimento do trabalho apresentado em Cunha (2010) encontra-se em Cunha e Marinho (2012).

${ }^{3}$ Rossari defende essa hipótese ao estudar conectores reformulativos do francês, como de toute façon, quoi quil en soit e enfin. 
${ }^{4}$ Para defender que alguns conectores reformulativos do francês criam relações de discurso, Rossari $(1993,2000)$ se vale de enunciados fabricados. Quando a autora estuda enunciados autênticos, esses são enunciados totalmente isolados de seu contexto de produção, o que pode colocar sob suspeita a validade de suas conclusões.

${ }^{5}$ Goffman (2011, p. 13-14) define a noção de face como "o valor social positivo que uma pessoa efetivamente reivindica para si mesma através da linha que os outros pressupóem que ela assumiu durante um contato particular”. Já a noção de território diz respeito aos direitos que cada pessoa reivindica e à defesa desses mesmos direitos. Os direitos que formam o território de cada um constituem um campo de objetos ou uma reserva, cujos limites são habitualmente preservados e defendidos (GOFFMAN, 1973).

${ }^{6}$ A memória discursiva diz respeito ao "conjunto de saberes conscientemente partilhados pelos interlocutores" (BERRENDONER, 1983, p. 230).

${ }^{7} \mathrm{I}$ = intervenção; $\mathrm{A}$ = ato; $\mathrm{p}=$ principal; $\mathrm{s}=$ subordinado.

${ }^{8}$ No modelo modular, a noção de tópico é definida como "uma informação identificável e presente na consciência dos interlocutores, que constitui, para cada ato, o ponto de ancoragem mais imediatamente pertinente, mantendo uma relação de 'a propósito' (aboutness) com a informação ativada por esse ato" (ROULET; FILLIETTAZ; GROBET, 2001, p. 255).

${ }^{9} \mathrm{O}$ endereço do guia é <http://189.28.128.100/nutricao/docs/geral/guia_alimentar_ conteudo.pdf>. Acesso: 05/10/2013.

${ }^{10}$ As cinco reportagens estudadas por Cunha (2008) não apresentam nenhuma relação de reformulação. No gênero notícia, próximo da reportagem, Duarte (2008) também não identificou nenhuma relação de reformulação nos oito exemplares que estudou. Já em Cunha (2013), das 449 relaçóes de discurso identificadas no corpus formado por sequências narrativas de dezesseis reportagens, apenas treze (2,89\%) são de reformulação.

\section{REFERÊNCIAS}

BECHARA, E. Moderna gramática portuguesa. Rio de Janeiro: Nova Fronteira, 2009. BERRENDONER, A. "Connecteurs pragmatiques” et anaphore. Cahiers de linguistique française, v. 5, p. 215-246, 1983.

BURGER, M. L'identité négociée: "rapports de place(s)" dans un entretien télédiffusé. Cahiers de linguistique française, v. 17, p. 09-33, 1995.

CUNHA, G. X. O sequenciamento de textos como estratégia discursiva: uma abordagem modular. 2008. 250f. Dissertação (Mestrado em Linguística) - Faculdade de Letras, Universidade Federal de Minas Gerais, Belo Horizonte, 2008. 
CUNHA, G. X. O tratamento do tópico em uma perspectiva modular da organização do discurso. Estudos Linguisticos, v. 38, p. 125-135, 2009.

CUNHA, G. X. A atuação do conector quando na organização de episódios da sequência narrativa. In: Anais do II Fórum Internacional de Análise do Discurso: discurso, texto e enunciação. Rio de Janeiro: UFRJ, 2010.

CUNHA, G. X. Análise do funcionamento atípico do conector quando como marca de reformulação. ReVEL, v. 9. n. 17, 2011.

CUNHA, G. X. A articulação discursiva do gênero artigo de opinião à luz de um modelo modular de análise do discurso. Filologia e Linguistica Portuguesa, v. 14, p. 73-97, 2012.

CUNHA, G. X. A construção da narrativa em reportagens. 2013. 601f. Tese (Doutorado em Linguística) - Faculdade de Letras, Universidade Federal de Minas Gerais, Belo Horizonte.

CUNHA, G. X.; MARINHO, J. H. C. O conector quando e o encadeamento de episódios da narrativa jornalística. Cadernos de Estudos Linguísticos, v. 54.2, 2012, p. 187-203.

DUARTE, R. J. A marcação das relações textuais em textos de gêneros do dominio jornalístico: uma abordagem modular. 2008. 205f. Dissertação (Mestrado em Linguística) - Faculdade de Letras, Universidade Federal de Minas Gerais, Belo Horizonte, 2008.

FILLIETTAZ, L. Négociation, textualisation et action: le concept de négociation dans le modèle genevois de l'organisation du discours. In: GROSJEAN, M.; MONDADA, L. (Org.) La négociation au travail. Lyon: Presses universitaires de Lyon. 2004, p. 69-96. FILLIETTAZ, L.; ROULET, E. The Geneva Model of discourse analysis: an interactionist and modular approach to discourse organization. Discourse Studies 4(3), p. 369-392, 2002.

GOFFMAN, E. La mise em scène de la vie quotidienne: les relations em public. v. 2. Paris: Les éditions de minuit, 1973.

GOFFMAN, E. Ritual de interação: ensaios sobre o comportamento face a face. Petrópolis: Vozes, 2011.

GROBET, A. Lidentification des topiques dans les dialogues. 2000. 513f. Tese (Doutorado em Linguística) - Faculdade de Letras, Universidade de Genebra, Genebra, 2000 .

KERBRAT-ORECCHIONI, C. Análise da conversação: princípios e métodos. São Paulo: Parábola Editorial, 2006. 
MANN, W. C.; THOMPSON, S. A. Relational propositions in discourse. Discourse Processes, v. 9, p. 57-90, 1986.

MARINHO, J. H. C. O funcionamento discursivo do item "onde": uma abordagem modular. 2002. 305f. Tese (Doutorado em Linguística) - Faculdade de Letras, Universidade Federal de Minas Gerais, Belo Horizonte, 2002.

MARINHO, J. H. C. Uma abordagem modular e interacionista da organização do discurso. Revista da Anpoll, v. 16. p. 75-100. 2004.

MARINHO, J. H. C; PIRES, M. S. O.; VIllELA, A. M. N. (Org.) Análise do discurso: ensaios sobre a complexidade discursiva. Belo Horizonte: CEFET-MG, 2007.

MOESCHLER, J. Ordre temporel, narration et analyse du discours. Cahiers de linguistique française, v. 18, p. 299-328, 1996.

NEPOMUCENO, A. R. Uma abordagem funcionalista das relaçôes retóricas em anúncios publicitários. 2013. 320f. Tese (Doutorado em Linguística) - Faculdade de Letras, Universidade Federal de Minas Gerais, Belo Horizonte.

ROSSARI, C. Les opérations de reformulation: analyse du processus et des marques dans une perspective contrastive français-italien. Berne: Lang, 1993.

ROSSARI, C. Connecteurs et relations de discours: des liens entre cognition et signification. Nancy: Presses Universitaires de Nancy, 2000.

ROULET, E. The description of text relation markers in the Geneva model of discourse organization. In: FISCHER, K (Ed.). Approaches to Discourse Particles. Amsterdam: Elsevier, 2006, p. 115-131.

ROULET, E.; FILLIETTAZ, L.; GROBET, A. Un modèle et un instrument d'analyse de l'organisation du discours. Berne: Lang, 2001.

RUFINO, J. A. As minhas meninas: análise de estratégias discursivas em canções buarqueanas produzidas no período da Ditadura Militar. 2011. 337f. Tese (Doutorado em Linguística) - Faculdade de Letras, Universidade Federal de Minas Gerais, Belo Horizonte, 2011.

TABOADA, M. Discourse markers as signal (or not) of rhetorical relations. Journal of Pragmatics, v. 38, n. 4, 2006, p. 567-592. 